\title{
Shear Behavior of Concrete Beams Reinforced with GFRP Shear Reinforcement
}

\author{
Heecheul Kim, Min Sook Kim, Myung Joon Ko, and Young Hak Lee \\ Department of Architectural Engineering, Kyung Hee University, 1732 Deogyeong-daero, Giheung-gu, Yongin-si, \\ Gyeonggi-do 446-701, Republic of Korea \\ Correspondence should be addressed to Young Hak Lee; leeyh@khu.ac.kr
}

Received 5 August 2015; Revised 23 September 2015; Accepted 27 September 2015

Academic Editor: Gonzalo Martínez-Barrera

Copyright (C) 2015 Heecheul Kim et al. This is an open access article distributed under the Creative Commons Attribution License, which permits unrestricted use, distribution, and reproduction in any medium, provided the original work is properly cited.

\begin{abstract}
This paper presents the shear capacities of concrete beams reinforced with glass fiber reinforced polymer (GFRP) plates as shear reinforcement. To examine the shear performance, we manufactured and tested a total of eight specimens. Test variables included the GFRP strip-width-to-spacing ratio and type of opening array. The specimen with a GFRP plate with a $3 \times 2$ opening array showed the highest shear strength. From the test results, the shear strength increased as the strip-width-to-strip-spacing ratio increased. Also, we used the experimental results to evaluate whether the shear strength equations of ACI 318-14 and ACI 440.1R can be applied to the design of GFRP shear reinforcement. In the results, the ACI 440 equation underestimated the experimental results more than that of ACI 318.
\end{abstract}

\section{Introduction}

Several studies have been carried out on the flexural behavior of concrete beams with fiber reinforced polymer (FRP) tensile reinforcement because FRP materials have advantages such as corrosion resistance, light weight, machinability, workability, and high strength [1-5]. Most FRP shear reinforcement for concrete members has been studied as a means of retrofitting. Hawileh et al. [6] and Al-Tamimi et al. [7] suggested techniques that involved externally bonding carbon fiber reinforced polymer (CFRP) laminates or sheets to reinforced concrete members. Hassan and Rizkalla [8] researched the bonding strength of FRP plates that were either embedded or attached to the exterior of concrete members. However, typical shear reinforcement (stirrup) for concrete members is difficult to fabricate with FRP materials because of their brittle nature and unidirectional characteristics. Therefore, FRP shear reinforcement has not yet been sufficiently investigated. The strength of the bent portion is significantly less than that of the straight part of FRP rods; hence several codes and design guidelines have specified the reduced capacity of FRP stirrups caused by bending the bars [9-12]. Recent studies investigated the shear capacities of FRP stirrups and proposed an equation of shear strength [12-15]. Kim et al. proposed a new type of FRP shear reinforcement as a substitute for steel stirrups [16]. Plate-type FRP shear reinforcement has better constructability and easier fabrication than FRP stirrups. Also, plate shear reinforcement does not reduce the strength by concentrating stress in the bent portion. In an earlier paper, the types of FRP and shape of reinforcement did not significantly affect the shear strength.

In this paper, considering economics and ease of fabrication, we use a lattice shaped GFRP material for shear reinforcement. To evaluate the applicability of FRP plates for shear reinforcement, shear tests were conducted using concrete beams embedded with GFRP plates with openings, considering the array of the openings and the GFRP strip-widthto-spacing ratio as the main variables. We also analyzed the failure modes and strain distributions.

\section{Experimental Investigation}

2.1. Experimental Materials. Following ASTM C39 [17], we tested seven cylindrical specimens of $150 \mathrm{~mm}$ diameter and $300 \mathrm{~mm}$ height. The average compressive strength of the 28day concrete was $44.6 \mathrm{MPa}$. Ten deformed steel bars with diameter of $25 \mathrm{~mm}$ and yield strength of $500 \mathrm{MPa}$ were used 
TABLE 1: Details of the experimental variations of the GFRP plate designs.

\begin{tabular}{|c|c|c|c|c|c|}
\hline \multirow[b]{2}{*}{ Specimen } & \multicolumn{5}{|c|}{ GFRP plate } \\
\hline & Type & $\begin{array}{c}f_{f u} \\
(\mathrm{MPa})\end{array}$ & $\begin{array}{l}\text { Width }\left(w_{f}\right) \\
(\mathrm{mm})\end{array}$ & $\begin{array}{c}\text { Thickness }(t) \\
(\mathrm{mm})\end{array}$ & $\begin{array}{l}\text { Center-to-center spacing of vertical strips }(s) \\
\qquad(\mathrm{mm})\end{array}$ \\
\hline A-1 & A & 480 & 20 & 4 & 340 \\
\hline A-2 & A & 480 & 30 & 4 & 340 \\
\hline A-3 & A & 480 & 50 & 4 & 340 \\
\hline A- 4 & A & 480 & 70 & 4 & 340 \\
\hline A-5 & A & 480 & 65 & 4 & 170 \\
\hline A-6 & A & 480 & 70 & 4 & 110 \\
\hline B-3 & $\mathrm{B}$ & 480 & 37.5 & 4 & 230 \\
\hline $\mathrm{C}-3$ & $\mathrm{C}$ & 480 & 37.5 & 4 & 230 \\
\hline
\end{tabular}

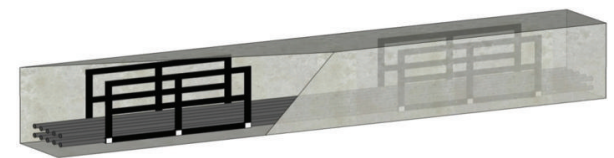

FIGURE 1: Schematic view of a concrete beam reinforced with GFRP plates.

as longitudinal reinforcement. We used GFRP plates with openings embedded in the concrete as shear reinforcement. The tensile test of the FRP was conducted based on CSA S806-02 [10]. The tensile stress was $480 \mathrm{MPa}$. Figure 1 shows a schematic view of a specimen.

2.2. Specimen Details. We considered the array of openings, GFRP strip-width-to-spacing ratio, and the amount of reinforcement as variables. The GFRP plates were manufactured in three shapes as shown in Figures 2 and 3. Each plate had the same total area $\left(b_{f} \times h_{f}\right)$; the A-Type had a $2 \times 2$ opening array, B-Type a $3 \times 2$ opening array, and C-Type a $3 \times 3$ opening array. All the intersections of the horizontal $\left(0^{\circ}\right)$ and vertical $\left(90^{\circ}\right)$ components made right angles. The difference in the width of the horizontal and vertical components of each plate provided variants within each type of opening array. Details of the three plate designs and the variations within each type are given in Table 1.

We tested a total of eight concrete beams embedded with GFRP plates with openings. Figure 4 illustrates how we placed GFRP plates in the specimens depending on their shapes. The anchorage length $\left(l_{d}\right)$ was $300 \mathrm{~mm}$, far from the points of support. The total span $(L)$ and clear span $\left(l_{n}\right)$ were $2700 \mathrm{~mm}$ and $2100 \mathrm{~mm}$, respectively. The thickness of the concrete cover was $40 \mathrm{~mm}$, and the shear span-to-depth ratio was 2.4. All the specimens were reinforced using ten deformed steel bars with a diameter of $25 \mathrm{~mm}$ in two layers to ensure shear failure prior to flexural failure in the beam tests.

2.3. Test Setup. Load was applied to each specimen at a rate of $5 \mathrm{kN} / \mathrm{min}$ using a hydraulic jack with a maximum capacity of $5000 \mathrm{kN}$, as shown in Figure 5 . The force generated by the hydraulic jack was transmitted to the center of a steel spreader beam installed to apply two-point loading to the beam specimen. A load cell attached to the bottom of the jack measured the magnitude of the loading. A linear variabledifferential transducer (LVDT) installed at the bottom center of the specimen measured the vertical displacement. As illustrated in Figure 5, we installed four strain gauges at the center of the horizontal and vertical components of each FRP plate. A data logger collected load, displacement, and strain data.

\section{Shear Strength Equation}

Figure 6 defines the width of the GFRP strip $\left(w_{f}\right)$, effective depth $(d)$, and spacing $(s)$.

Several mechanisms contribute to the shear capacities of reinforced concrete beams, such as the concrete, shear reinforcement, mechanical aggregates interlocking, and dowel action of the tensile reinforcement. Shear reinforcement has a mechanism for resistance to shear, as shown in Figure 7. For this paper, we replaced the stirrup with a vertical strip of the FRP shear reinforcement. The function of the horizontal strip is to anchor the vertical strips. The horizontal projection of the crack is taken as $d$. The number of FRP vertical strips crossing the crack is $d / s$. Assuming that all FRP vertical strips reach their failure, the shear strength of the shear reinforcement can be obtained from

$$
V_{s}=\frac{A_{f} f_{f u} d}{s} .
$$

We assume the crack angle to be $45^{\circ}$ when calculating the shear strength of the shear reinforcement. The tensile behavior of the FRP is characterized by a linearly elastic stress-strain relationship up to failure. Hence, shear failure is assumed to occur after fracture of the shear reinforcement.

3.1. Shear Strength Equation in ACI 318-14. As shown in (2), the shear strength equation in ACI 318-14 [15] provides the sum of the shear strength of the concrete and the shear reinforcement. The shear strength of concrete can be obtained from (3), which includes the longitudinal steel ratio $\left(\rho_{w}\right)$ and shear span-to-depth ratio $(a / d)$. Equation (4) calculates the shear strength of the shear reinforcement material based on the concept of the shear strength of a steel stirrup in ACI 31814. Calculating the shear strength of FRP plates requires the area of the vertical components $\left(A_{f}\right)$, the number of vertical 


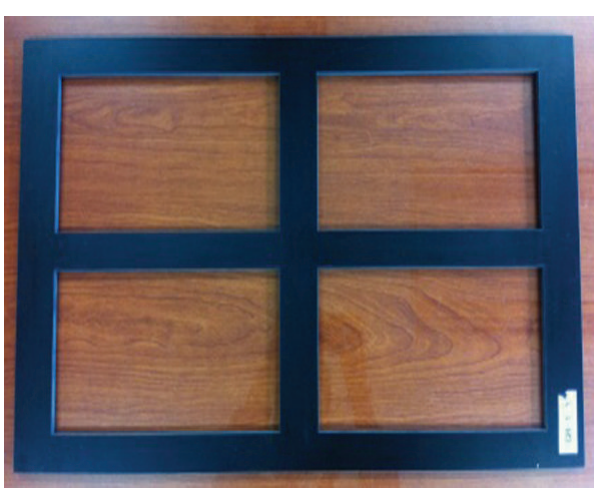

(a) A-Type

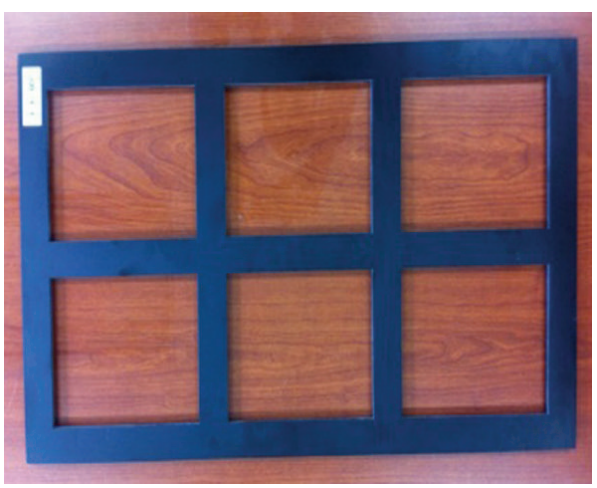

(b) B-Type

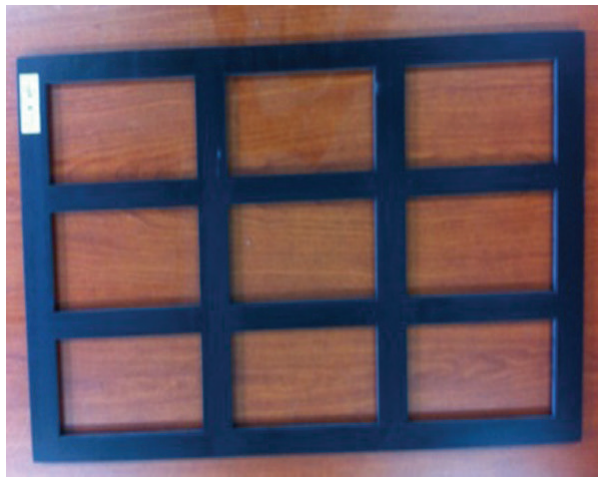

(c) C-Type

FIGURE 2: Designs of the three experimental GFRP plates.

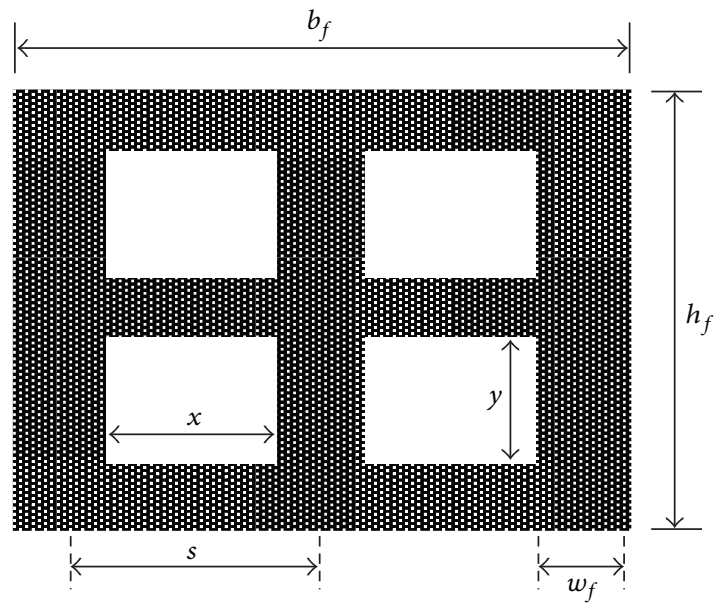

FIGURE 3: Notation of geometry for a GFRP plate.

components $(n)$, and the tensile strength in the critical shear span, as in (4). The area of the plate $\left(A_{f}\right)$ can be obtained from (5), and the number of vertical components in the critical shear span can be obtained from (6):

$$
\begin{aligned}
V_{n} & =V_{c}+V_{f}, \\
V_{c} & =\left(0.16 \sqrt{f_{c}^{\prime}}+\frac{17 \rho_{w} d}{a}\right) b_{w} d, \\
V_{f, 318} & =n A_{f} f_{f u} \sin \alpha,
\end{aligned}
$$

$$
\begin{aligned}
A_{f} & =2 t_{f} w_{f}, \\
n & =\frac{d}{s}(1+\cot \alpha) .
\end{aligned}
$$

3.2. Shear Strength Equation in ACI 440.1R-06. ACI 440.1R provides a shear strength equation for concrete with FRP rebar flexural reinforcement. However, in this paper, we adopted the shear strength equation for concrete in ACI 318 because we used steel flexural reinforcement. The shear strength of the shear reinforcement can be calculated with (7). Equation (8) gives the stress level in the FRP shear reinforcement at its utmost for use in design. ACI 440.1R addresses the reduced shear strength of stirrups caused by bending the FRP bars, as shown in (9). Because our GFRP shear reinforcement is a plate type, we did not consider the bend portion. Consider

$$
\begin{aligned}
V_{f, 440} & =n A_{f} f_{f v d} \sin \alpha, \\
f_{f v d} & =0.004 E_{f} \leq f_{f b}, \\
f_{f b} & =\left(\frac{0.05 r_{b}}{d}+0.3\right) f_{f u v} .
\end{aligned}
$$

\section{Experimental Test Results}

4.1. Failure Mode. As shown in Figure 8, flexural cracks occurred at the tension surface in the middle of the span, followed by the formation of inclined cracks. As the inclined 


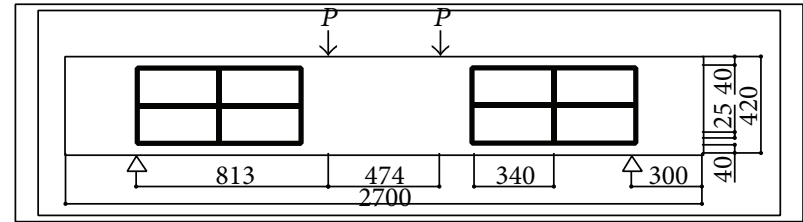

(a) A-1

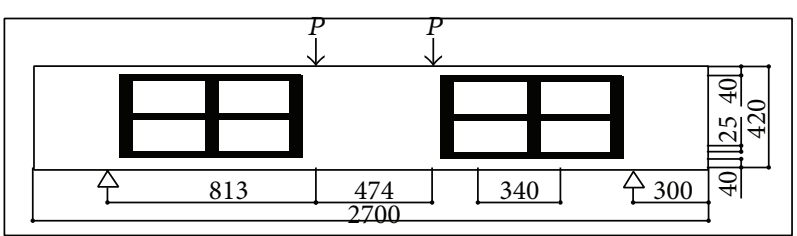

(c) A-3

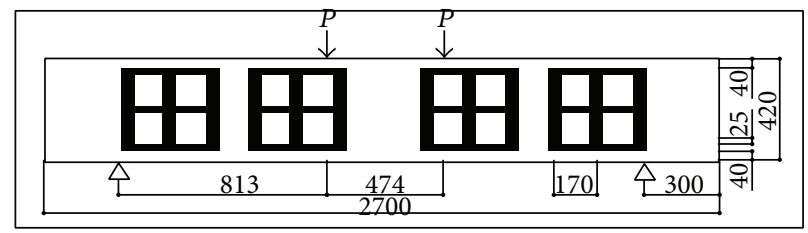

(e) A-5

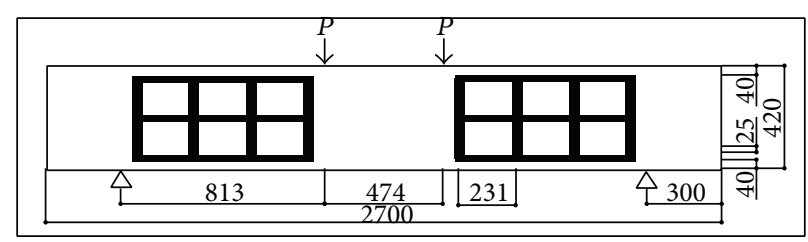

(g) B-3

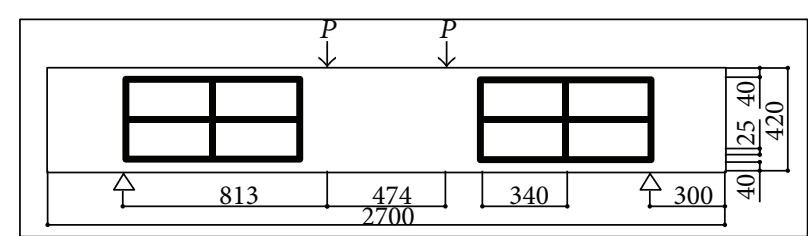

(b) A-2

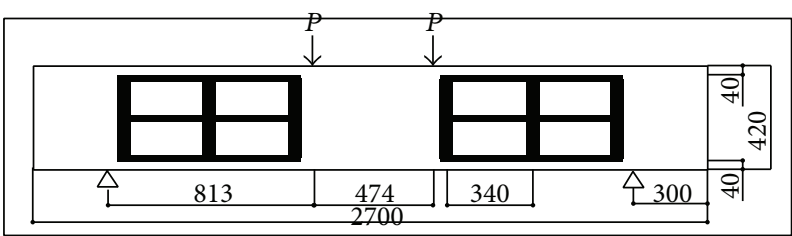

(d) A-4

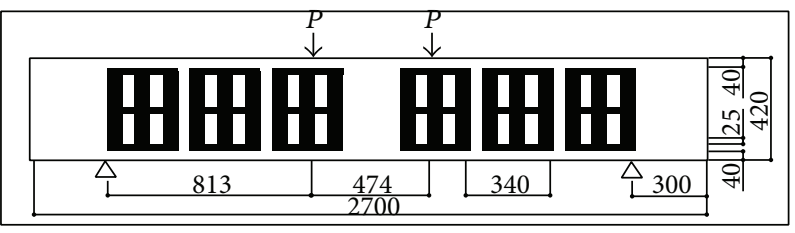

(f) A-6

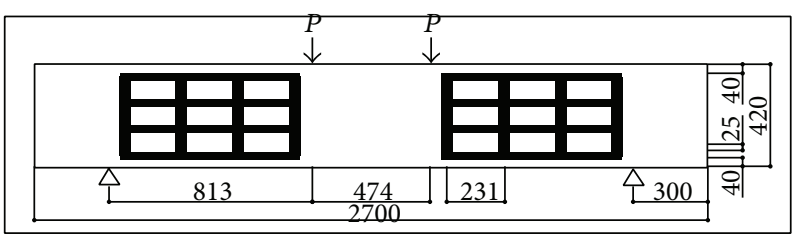

(h) C-3

FIGURE 4: Arrangement of GFRP plates in specimens.

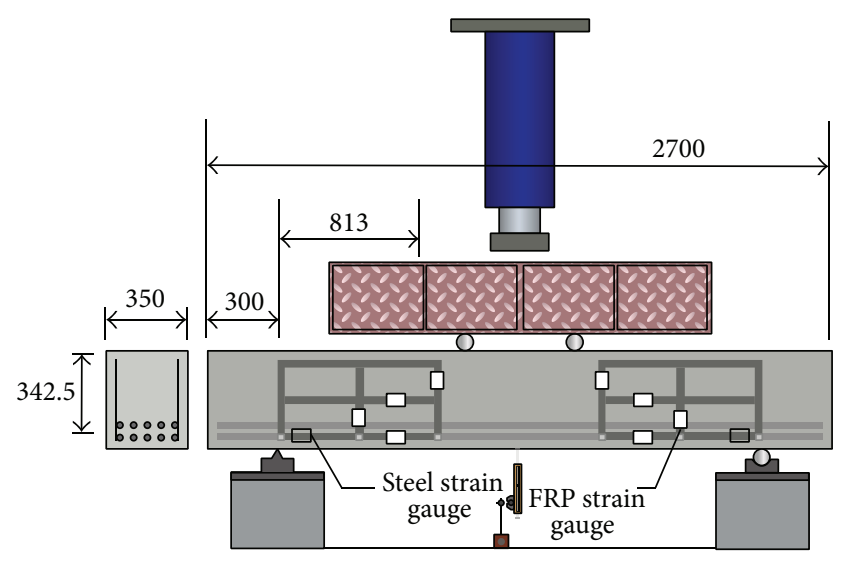

Figure 5: Test setup of typical specimen.

cracks propagated toward the loading point, concrete crushing occurred in the upper end region of the inclined crack at the final stage of failure. In other words, shear-compression failure (shear failure from the diagonal crack) occurred. The initial crack appeared at a load of approximately $150 \mathrm{kN}$ in the middle of the beam. It appeared to be a flexural crack caused by tensile stress due to bending. At approximately $200 \mathrm{kN}$, a flexural shear crack appeared at effective depth, far from

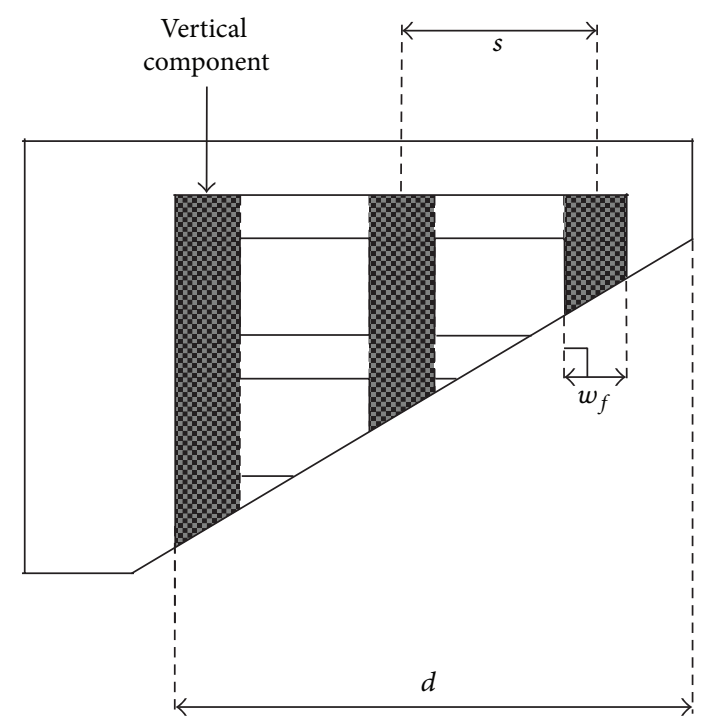

FIGURE 6: Definitions of $w_{f}, d$, and $s$.

the point of support. At approximately $450 \mathrm{kN}$, the diagonal crack appeared, and then a flexural shear crack followed. The reinforcement of the GFRP plates increased resistance to the shear force as the diagonal crack occurred and elongated. 


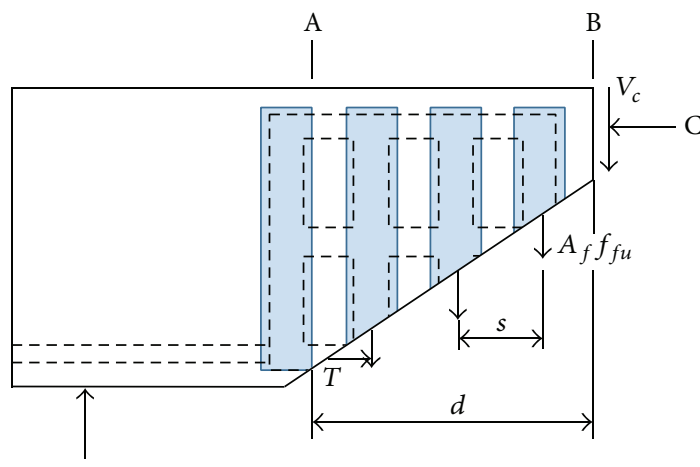

FIGURE 7: Shear resistance by FRP shear reinforcement.

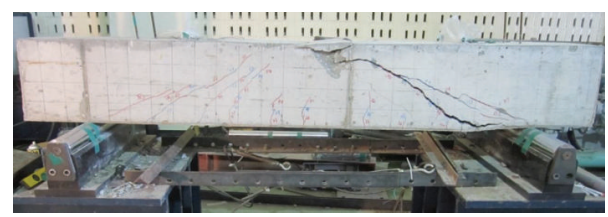

(a) A-2

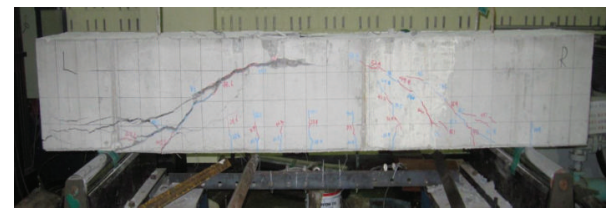

(b) A-3

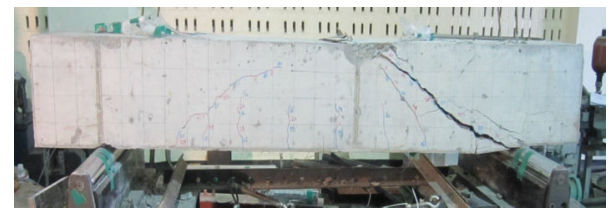

(c) B-3

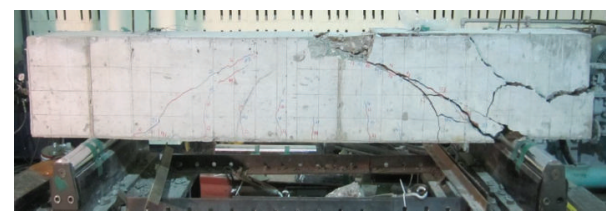

(d) C-3

FIGURE 8: Shear-compression failure in specimens.

When the GFRP plate reached the limit of its tensile strength, it fractured, and specimen failure occurred.

We observed two typical failure modes in response to the amount of reinforcement provided. First, all the specimens except A-5 and A- 6 fractured, and the plates ruptured after they had demonstrated their maximum shear strength. The concrete cover of specimens A-5 and A- 6 , on the other hand, fractured before the plate reached its maximum shear strength. The specimens showed two different failure modes because the size of the openings in the plates and the ratio of the area of the openings varied. This result could also be caused by a lack of concrete coverage. Therefore if the opening size, ratio of the area of openings, and sufficient concrete
TABLE 2: Maximum loading and shear strength test results.

\begin{tabular}{lccc}
\hline Specimen & $\begin{array}{c}P_{\max } \\
(\mathrm{kN})\end{array}$ & $\begin{array}{c}V_{\max } \\
(\mathrm{kN})\end{array}$ & Failure mode \\
\hline A-1 & 573.20 & 286.60 & Shear \\
A-2 & 591.73 & 295.87 & Shear \\
A-3 & 776.83 & 388.42 & Shear \\
A-4 & 899.76 & 449.88 & Shear \\
A-5 & 748.74 & 374.37 & Shear \\
A-6 & 950.27 & 475.14 & Shear \\
B-3 & 872.64 & 436.32 & Shear \\
C-3 & 757.93 & 378.97 & Shear \\
\hline
\end{tabular}

TABLE 3: Size and opening dimensions of FRP reinforcements.

\begin{tabular}{lccccc}
\hline Specimen & $b_{f}$ & $h_{f}$ & $x$ & $y$ & Opening/FRP plate $(\%)$ \\
\hline A-1 & 700 & 340 & 320 & 125 & 67.23 \\
A-2 & 710 & 340 & 310 & 125 & 64.21 \\
A-3 & 730 & 340 & 290 & 125 & 58.42 \\
A-4 & 750 & 340 & 270 & 125 & 52.94 \\
A-5 & 405 & 340 & 97.5 & 125 & 35.40 \\
A-6 & 290 & 340 & 40 & 125 & 20.28 \\
B-3 & 730 & 340 & 193.3 & 125 & 58.42 \\
C-3 & 730 & 340 & 193.3 & 83 & 58.19
\end{tabular}

coverage conditions are met, the plate will demonstrate maximum shear strength, and the specimen will provide effective shear performance. The test results for maximum loading and maximum shear strength are summarized in Table 2 .

4.2. Array of Openings and Ratio of Openings. Figure 9 shows the measurements used for each plate type and the variations of those types. The total width and height of the plates are marked as $b_{f}$ and $h_{f}$, respectively; the width and height of each opening are marked as $x$ and $y$, respectively. The opening size and ratio of the area of openings are listed in Table 3. Ratio of the area of openings is the area of all openings divided by the total area of the plate. We designed the plate to meet the following conditions: both the width $(x)$ and depth $(y)$ of the GFRP plate openings described in Table 3 should be at least $100 \mathrm{~mm}$, and ratio of the area of openings should be higher than $50 \%$.

In specimens A-5 and A-6, which did not meet those conditions, the concrete exhibited brittle failure before the plate reached the limit of its maximum strength. Specimen C-3, which met the ratio condition but not the size condition, showed lower maximum shear strength than Specimen B3 did, which met both conditions. Therefore, if the opening size is larger than $100 \mathrm{~mm}$ and ratio of the area of openings is higher than $50 \%$, sufficient integration between the FRP shear reinforcement and the concrete can be expected.

Figure 10 shows the load-deflection relations for three specimens (A-3, B-3, and C-3) with the same ratio of the area of openings. All three specimens exhibited the same behavior before shear failure. This test result indicates that Specimen 


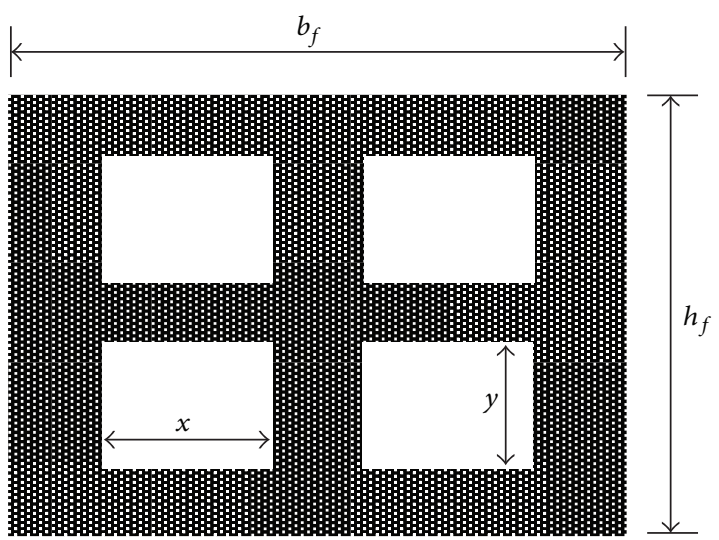

FIGURE 9: Dimensions of a GFRP plate and its openings.

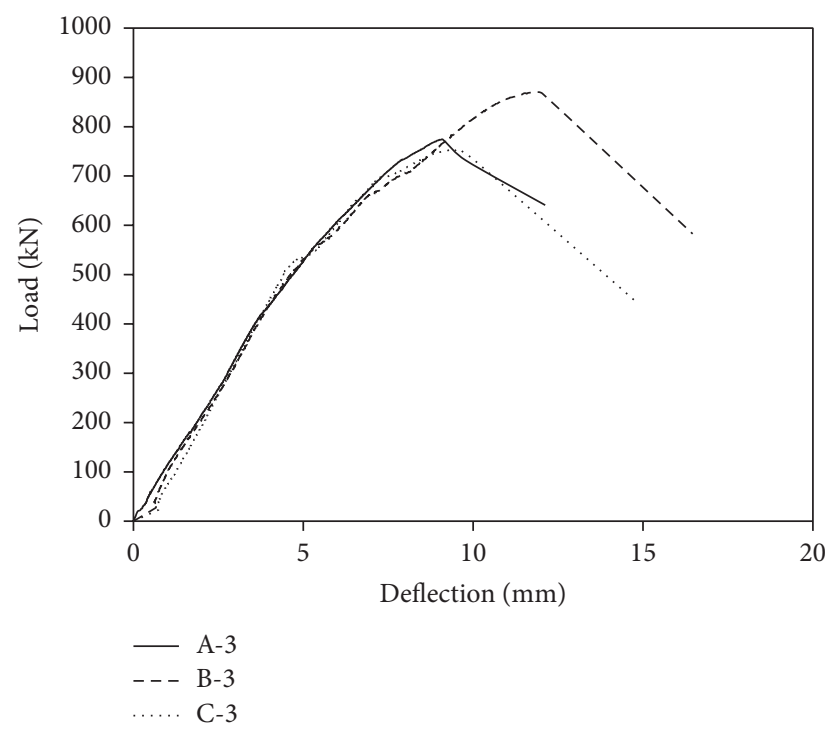

FIGURE 10: Load-deflection curves for three different arrays of openings in GFRP shear reinforcement.

B-3 had more effective integration than A-3 because of a larger bonded area between the concrete and the B-3 plate. Although C-3 had the largest bonded area among the three, its depth $(y)$ was less than $100 \mathrm{~mm}$. Specimen B-3 showed the largest shear strength. Therefore, to increase shear capacity, the bonded area between the FRP plate and the concrete should be maximized while meeting the conditions of opening size and ratio of the area of openings.

4.3. Amount of Shear Reinforcement. To examine the influence of the amount of shear reinforcement on shear strength, we designed each specimen with different amounts of reinforcement. The amount of shear reinforcement was the product of the number of vertical components in the critical shear span $(n)$, the width of the vertical components $\left(w_{f}\right)$, and the thickness of the vertical components $\left(t_{f}\right)$, that is, $\left(n \times w_{f} \times t_{f}\right)$. Figure 11 shows the load-deflection relations for specimens with various shear reinforcement areas. The amount of shear reinforcement for the experimental variants

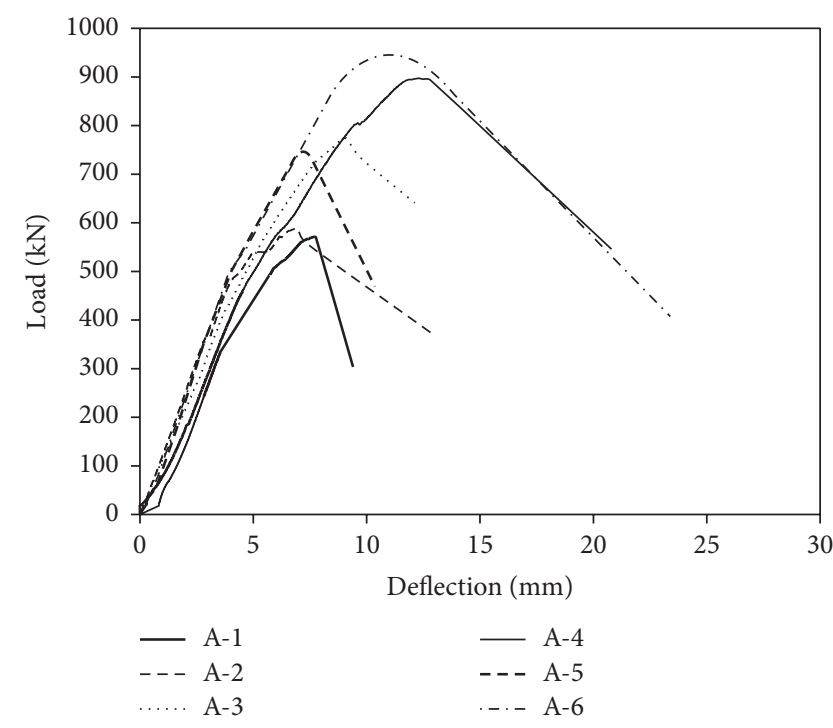

FIGURE 11: Load-deflection curves for amount of shear reinforcement.

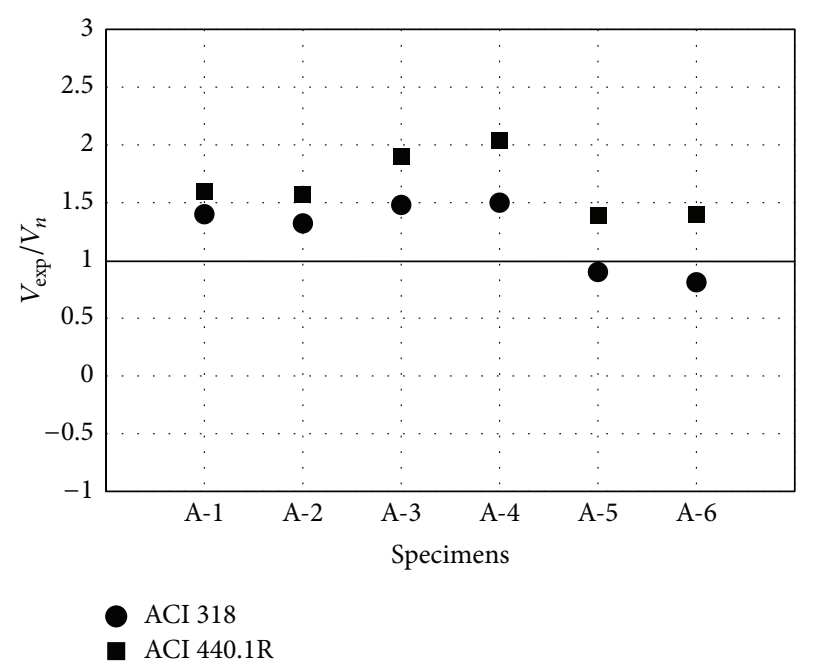

FIGURE 12: Ratio of test results to theoretical predictions of shear strength $\left(V_{\exp } / V_{n}\right)$.

A-1 to A-4 was controlled by the different widths of the vertical strips; for A-5 and A-6, it was controlled by different spacing of the vertical strips. Figure 12 shows the ratio of shear strength for six specimens (A-1, A-2, A-3, A-4, A-5, and A-6) according to the amount of shear reinforcement. $V_{\text {exp }}$ was obtained from the experiment that measured shear strength, and $V_{n}$ was obtained from the equation by which shear strength was calculated.

All of the specimens, except A-5 and A-6, showed similar ratios of shear strength. In contrast, specimens A-5 and A6 showed only $80-90 \%$ of the calculated value. Because the plate had insufficient opening size and ratio of the area of openings, brittle failure occurred in specimens A-5 and A-6 before the shear reinforcement reached the limit of its maximum strength. 
TABLE 4: Experimental results and ratio of shear strength.

\begin{tabular}{lcccccc}
\hline Specimen & $\begin{array}{c}V_{c} \\
(\mathrm{kN})\end{array}$ & $\begin{array}{c}V_{f, 318} \\
(\mathrm{kN})\end{array}$ & $\begin{array}{c}V_{f, 440} \\
(\mathrm{kN})\end{array}$ & $\begin{array}{c}V_{\exp } \\
(\mathrm{kN})\end{array}$ & $V_{\text {exp }} / V_{n, 318}$ & $V_{\text {exp }} / V_{n, 440}$ \\
\hline A-1 & 164.55 & 38.68 & 16.12 & 288.60 & 1.41 & 1.60 \\
A-2 & 164.55 & 58.02 & 24.18 & 295.87 & 1.33 & 1.57 \\
A-3 & 164.55 & 96.71 & 40.29 & 388.42 & 1.49 & 1.90 \\
A-4 & 164.55 & 135.39 & 56.41 & 449.88 & 1.50 & 2.04 \\
A-5 & 164.55 & 251.44 & 104.76 & 374.37 & 0.90 & 1.39 \\
A-6 & 164.55 & 418.47 & 174.36 & 475.14 & 0.81 & 1.40 \\
B-3 & 164.55 & 107.22 & 44.67 & 436.32 & 1.61 & 2.09 \\
C-3 & 164.55 & 107.22 & 44.67 & 378.97 & 1.39 & 1.81 \\
\hline
\end{tabular}

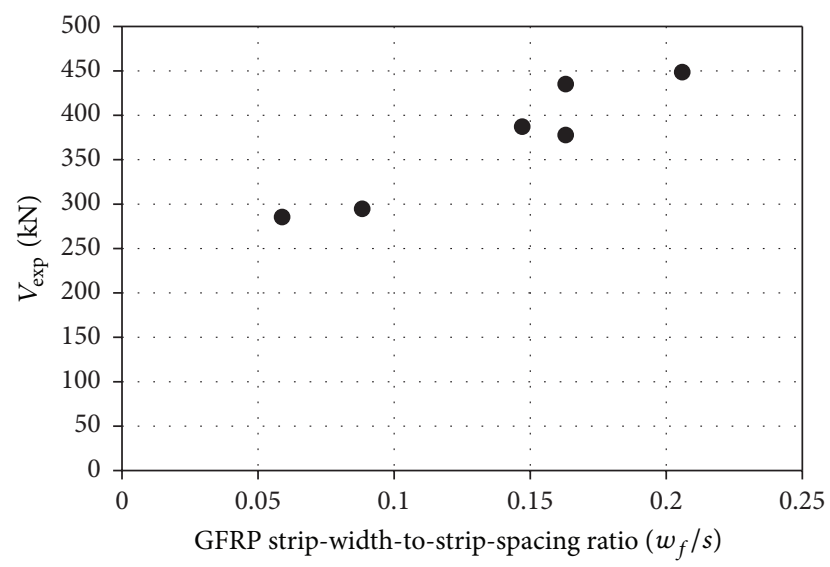

FIGURE 13: Effect of the GFRP strip-width-to-spacing ratio on shear strength.

Figure 13 shows shear strength according to the width-tospacing ratio of the strip for all of the specimens except the two that did not meet the opening size and ratio conditions (A-5 and A-6). The results indicate that the shear strength increases as the spacing-width ratio of a strip increases. As expected, effective shear-crack control is established by providing a larger bonded area to resist shear cracks. This bonded area increases as the width-to-spacing ratio increases.

\section{Comparison of Experimental Results and Shear Strength Equations}

Table 4 shows the shear strength of the concrete $\left(V_{c}\right)$, shear strength of the plate $\left(V_{f}\right)$, and maximum shear strength $\left(V_{n}\right)$, which is the sum of the shear strength of the concrete and of the plate, of the beam designed using the shear strength equations of ACI 318 and ACI 440-1R. The ratio of shear strength $\left(V_{\text {exp }} / V_{n}\right)$, which compares the maximum calculated shear strength $\left(V_{n}\right)$ and the experimental shear strength $\left(V_{\exp }\right)$, is also included in Table 4 . The shear strength equation in ACI 318-14 calculates the shear strength of concrete as a constant. As shown in Table 4, the mean value of the shear strength ratio $\left(V_{\exp } / V_{n}\right)$ is 1.46 with a standard deviation of 0.10 using ACI 318 , and the shear strength ratio $\left(V_{\exp } / V_{n}\right)$ of two values was between 1.33 and 1.61. On the other hand, ACI 440.1R gives a mean value 1.83 with a standard deviation of 0.21 , with a shear strength ratio of two values between 1.57 and 2.09. This verifies that the shear strength equation in ACI 318 can be used to predict the shear strength of concrete beams with embedded GFRP plates with openings, as long as the plate meets the minimum conditions for opening size and ratio of the area of openings. On the other hand, when using ACI $440.1 \mathrm{R}$, only $40 \%$ of the design strength was applied as tensile strength; therefore, the test results were underestimated.

\section{Conclusions}

In this study, to analyze the shear performance of concrete beams with embedded GFRP plates with openings, we selected the array of openings, ratio of the area of openings, amounts of shear reinforcement, and GFRP strip-width-tostrip-spacing ratio as variables. We used the shear strength equations in ACI 318-14 and ACI 440.1R to compare the experimental and theoretical shear strengths. We draw the following conclusions:

(1) The width and height of the opening should be larger than $100 \mathrm{~mm}$, and the ratio of the area of openings should be greater than $50 \%$ to obtain effective shear performance.

(2) Three different results from three different shapes of reinforcing plates show that increasing the bonded area between the GFRP plate and the concrete increases the performance of the shear reinforcement, provided the basic conditions are met.

(3) Analysis of the GFRP strip-width-to-spacing ratio showed that as the ratio increased, the bonded area increased, which improved resistance to shear cracks.

(4) The equations in ACI 318 and ACI 440.1R yielded generally conservative shear strength results. The ACI 318 code gives a mean value of 1.46 with a standard deviation of 0.1 . The ACI 440.1R code gives a mean value of 1.83 with a standard deviation of 0.2 . Therefore, the shear strength equation in ACI 318 was more applicable than that in ACI 440.1R to the GFRP platereinforced concrete beams.

\section{Notations}

a/d: Shear span-to-depth ratios

$A_{f}$ : Sectional area of a vertical strip of FRP plate $\left(\mathrm{mm}^{2}\right)$

$b_{w}$ : Web width $(\mathrm{mm})$

$d$ : Distance from extreme compression fiber to centroid of longitudinal tension reinforcement $(\mathrm{mm})$

$f_{c}^{\prime}$ : Specified compressive strength of concrete $(\mathrm{MPa})$

$f_{f u}$ : Specified tensile strength of FRP plate (MPa)

$n$ : Number of vertical components of the FRP plate within the critical shear span

$s$ : Center-to-center spacing of longitudinal shear reinforcement $(\mathrm{mm})$

$t_{f}$ : Thickness of FRP plate $(\mathrm{mm})$

$V_{c}$ : Nominal shear strength provided by concrete $(\mathrm{kN})$

$V_{\text {exp }}$ : Shear strength provided by experiment $(\mathrm{kN})$

$V_{f}$ : Nominal shear strength provided by FRP plate $(\mathrm{kN})$ 
$V_{n}:$ Nominal shear strength $(\mathrm{kN})$

$w_{f}$ : Width of FRP plate $(\mathrm{mm})$

$\alpha$ : Angle between shear reinforcement and longitudinal axis of the member $\left(^{\circ}\right.$ )

$\rho_{w}$ : Ratio of $A_{s}$ to $b_{w} d$.

\section{Conflict of Interests}

The authors declare that there is no conflict of interests regarding the publication of this paper.

\section{Acknowledgment}

This work was supported by a National Research Foundation of Korea (NRF) grant funded by the Korea government (MSIP) (NRF-2011-0016332).

\section{References}

[1] C. Higgins, G. T. Williams, M. M. Mitchell, M. R. Dawson, and D. Howell, "Shear strength of reinforced concrete girders with carbon fiber-reinforced polymer: experimental results," ACI Structural Journal, vol. 109, no. 6, pp. 805-814, 2012.

[2] F.-Y. Yeh and K.-C. Chang, "Size and shape effects on strength and ultimate strain in FRP confined rectangular concrete columns," Journal of Mechanics, vol. 28, no. 4, pp. 677-690, 2012.

[3] A. Mofidi and O. Chaallal, "Shear strengthening of RC beams with externally bonded FRP composites: effect of strip-widthto-strip-spacing ratio," Journal of Composites for Construction, vol. 15, no. 5, pp. 732-742, 2011.

[4] M. M. R. Taha, M. J. Masia, K.-K. Choi, P. L. Shrive, and N. G. Shrive, "Creep effects in plain and fiber-reinforced polymerstrengthened reinforced concrete beams," ACI Structural Journal, vol. 107, no. 6, pp. 627-635, 2010.

[5] C. Mazzotti, M. Savoia, and B. Ferracuti, "An experimental study on delamination of FRP plates bonded to concrete," Construction and Building Materials, vol. 22, no. 7, pp. 14091421, 2008.

[6] R. A. Hawileh, H. A. Rasheed, J. A. Abdalla, and A. K. AlTamimi, "Behavior of reinforced concrete beams strengthened with externally bonded hybrid fiber reinforced polymer systems," Materials and Design, vol. 53, pp. 972-982, 2014.

[7] A. K. Al-Tamimi, R. Hawileh, J. Abdalla, and H. A. Rasheed, "Effects of ratio of CFRP plate length to shear span and end anchorage on flexural behavior of SCC RC beams," Journal of Composites for Construction, vol. 15, no. 6, pp. 908-919, 2011.

[8] T. Hassan and S. Rizkalla, "Investigation of bond in concrete structures strengthened with near surface mounted carbon fiber reinforced polymer strips," Journal of Composites for Construction, vol. 7, no. 3, pp. 248-257, 2003.

[9] ACI Committee 440.1R, Guide for the Design and Construction of Concrete Reinforced with FRP Bars (ACI 440.1R-06), American Concrete Institute, Farmington Hills, Mich, USA, 2006.

[10] Canadian Standard Association (CSA), Design and Construction of Building Components with Fiber Reinforced Polymers (CSA S806-02), Canadian Standard Association (CSA), Mississauga, Canada, 2002.

[11] Intelligent Sensing for Innovative Structures (ISIS), Canada Reinforcing Concrete Structures with Fibre Reinforced Polymers (ISIS-M03-01), ISIS Canada Resource Centre, Winnipeg, Canada, 2001.
[12] M. R. Ehsani, H. Saadatmanesh, and S. Tao, "Bond of hooked glass fiber reinforced plastic (GFRP) reinforcing bars to concrete," ACI Materials Journal, vol. 92, no. 4, pp. 391-400, 1995.

[13] K. Ishihara, T. Obara, Y. Satao, T. Ueda, and Y. Kakuta, "Evaluation of ultimate strength of FRP rods at bent up portion," in Proceedings of the 3rd International Symposium on NonMetallic (FRP) Reinforcement for Concrete Structures, pp. 27-34, Sapporo, Japan, 1997.

[14] E. Shehata, R. Morphy, and S. Rizkalla, "Fibre reinforced polymer shear reinforcement for concrete members: behaviour and design guidelines," Canadian Journal of Civil Engineering, vol. 27, no. 5, pp. 859-872, 2000.

[15] A. K. El-Sayed, E. El-Salakawy, and B. Benmokrane, "Mechanical and structural characterization of new carbon FRP stirrups for concrete members," Journal of Composites for Construction, vol. 11, no. 4, pp. 352-362, 2007.

[16] D.-J. Kim, M. S. Kim, J. Choi, H. Kim, A. Scanlon, and Y. H. Lee, "Concrete beams with fiber-reinforced polymer shear reinforcement," ACI Structural Journal, vol. 111, no. 4, pp. 903-911, 2014.

[17] ASTM International, "Standard test method for compressive strength of cylindrical concrete specimens," ASTM C 39, ASTM International, West Conshohocken, Pa, USA, 2001. 

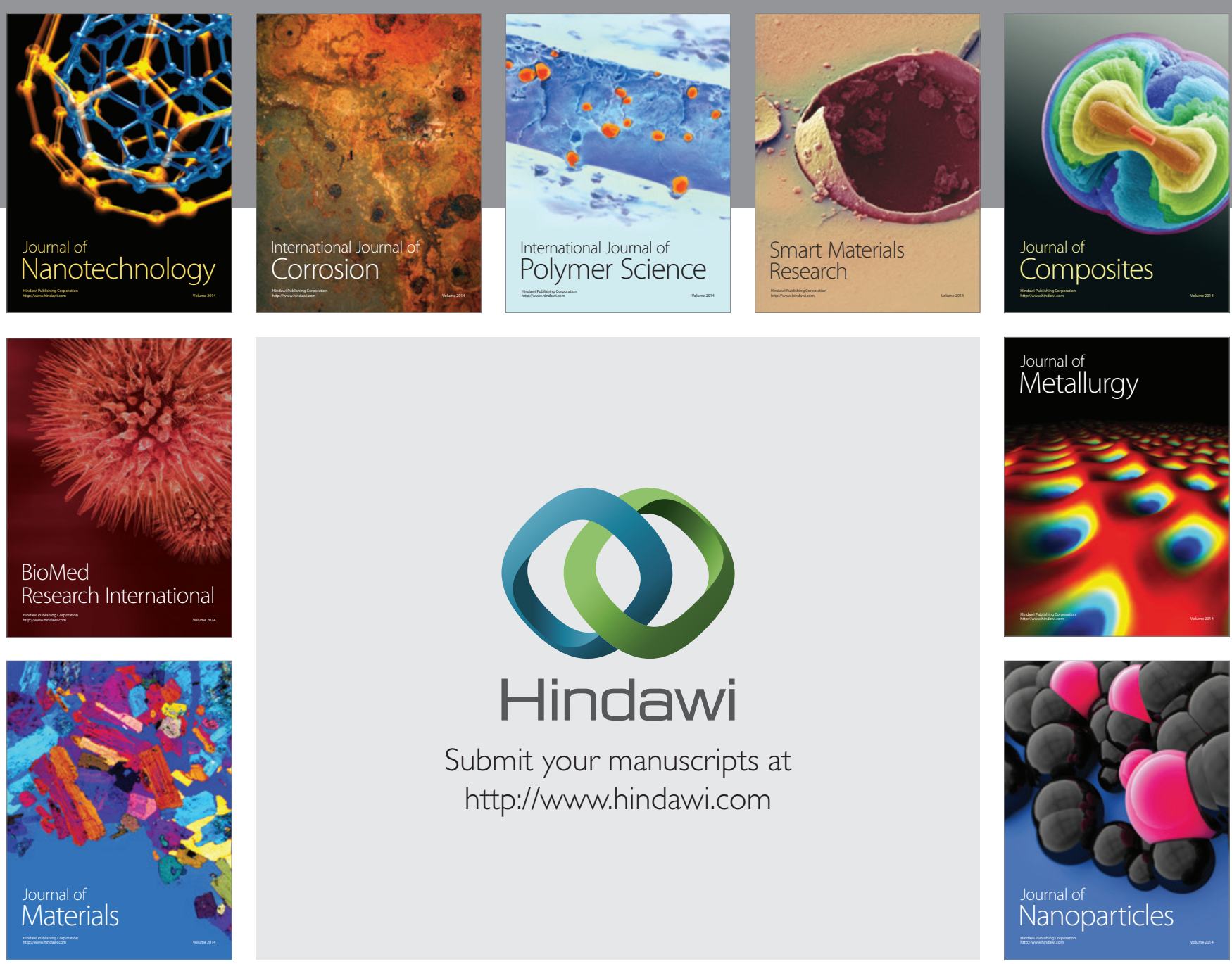

Submit your manuscripts at http://www.hindawi.com
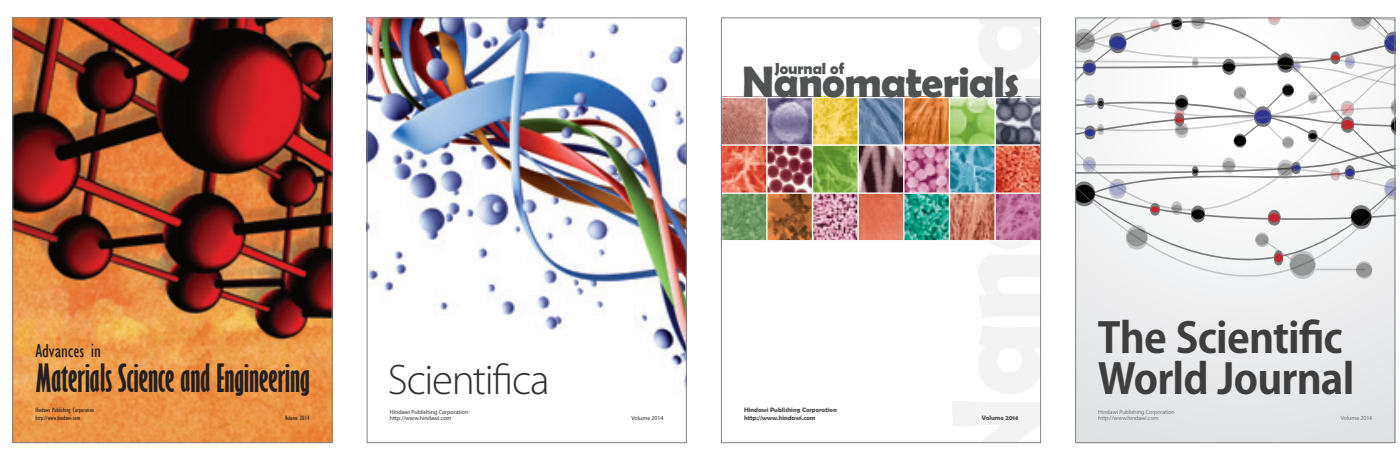

\section{The Scientific World Journal}
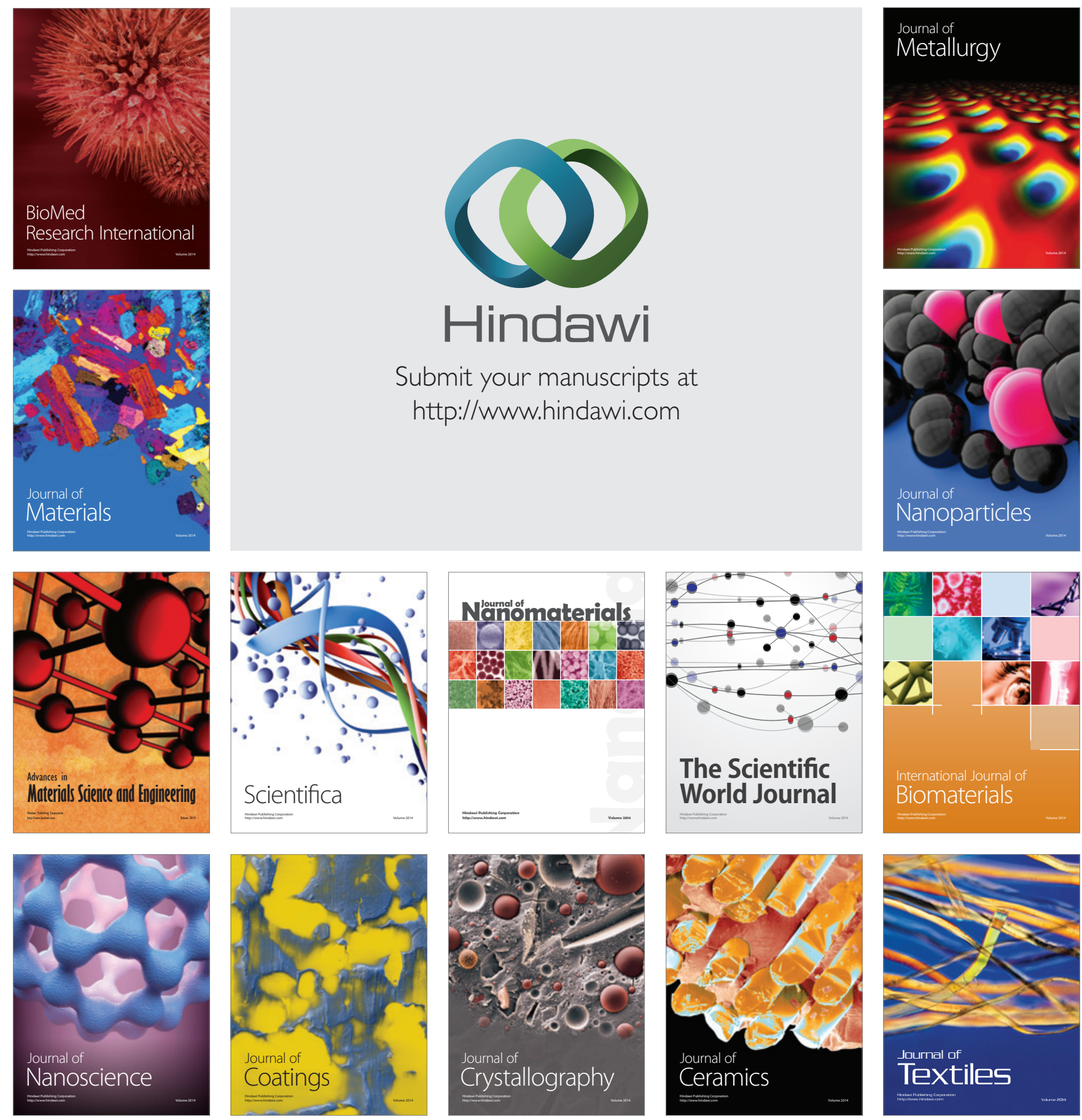